\title{
Rheumatoid blood decreases the adherence of polymorphonuclear cells (PMNs) to cultured endothelium
}

\author{
R C CHASTY, ${ }^{1} \mathrm{~K}$ A BROWN, ${ }^{1} \mathrm{~N}$ J SHEEHAN, ${ }^{1}$ A P KIRK, ${ }^{2}$ \\ J D PERRY, ${ }^{2}$ D MCCARTHY, ${ }^{3}$ AND D C DUMONDE
}

From the 'Department of Immunology, United Medical and Dental Schools, St Thomas's campus, London; the ${ }^{2}$ Department of Rheumatology, The London Hospital; and the ${ }^{3}$ Department of Biological Sciences, Queen Mary College, London

SUMMARY Rheumatoid sera and plasma inhibited the adherence of normal blood polymorphonuclear cells (PMNs) to cultured porcine endothelium. This inhibition of adhesion was not seen when PMNs were treated with the plasma or serum from normal subjects or patients with other inflammatory arthropathies. The abrogation of PMN adherence was directly related to the levels of circulating immune complexes and was not dependent upon the type of anti-inflammatory therapy that the patients were receiving nor on any of the recorded clinical parameters. A similar inhibition of adhesion was seen with heat induced aggregated human IgG (HAGG) provided that serum was present in the culture medium. In view of these results we propose that circulating immune complexes in RA may have a significant role in controlling the interaction of PMNs with vascular endothelium and in perpetuating the entry of these cells into the synovial fluid of the inflamed joints.

Key words: rheumatoid arthritis, neutrophils, margination, immune complexes.

In the preceding paper it was shown that rheumatoid sera inhibited the adherence of normal blood polymorphonuclear cells (PMNs) to monolayers of porcine endothelium.' The adherence of normal PMNs to nylon fibre columns is reported to be enhanced when the cells are suspended in the plasma, but not the serum, of patients with acute inflammatory disease ${ }^{2}$ and inhibited by the sera of patients receiving anti-inflammatory therapy. ${ }^{3}$ To characterise the inhibitory factor present in RA blood, samples of plasma and serum were prepared from patients with RA, whose clinical presentations were carefully recorded. Similar samples were obtained from patients with other inflammatory arthropathies and normal subjects. The adherence modifying activities of these plasma/serum samples were tested in a quantitative monolayer adhesion assay and screened for evidence of immunological abnormalities. After the observation that an inhibition of PMN adherence by the RA samples corre-

Accepted for publication 11 August 1986.

Correspondence to Dr K A Brown, Department of Immunology, The Rayne Institute, St Thomas's Hospital, London SE1 7EH. lated with their increased levels of circulating immune complexes further experiments were devised in which blood PMNs were cocultured with stable human IgG aggregates. When normal human serum was present in the assay these aggregates inhibited PMN adhesion, suggesting that immune complexes mediate the inhibitory activity present in the blood of patients with RA.

\section{Patients and methods}

PATIENTS

Sera and plasma were obtained from patients with RA attending the Rheumatology Department, The London Hospital. Aliquots of the samples were taken and stored at $-70^{\circ} \mathrm{C}$ until use. Of the 26 patients with RA investigated, six were receiving prednisolone therapy in conjunction with nonsteroidal anti-inflammatory drugs (NSAIDs), two penicillamine only, two gold and NSAIDs, two azathioprine and NSAIDs, and the remainder NSAIDs only. The disease activity of all the patients was assessed by an independent clinician. Blood samples were also obtained from three patients with 
psoriatic arthritis, two with ankylosing spondylitis, and one with systemic lupus erythematosus (SLE); the patient with SLE was receiving prednisolone, chloroquine, and NSAIDs, and the other five patients NSAIDs only. In addition, samples of serum and plasma were obtained from 20 healthy hospital personnel. All rheumatoid samples were screened for latex titres, IgG, IgM, and $\operatorname{Ig} A$ rheumatoid factor (RF) concentrations, immune complexes by the $\mathrm{Clq}$ binding and solid phase assay, and complement levels determined by measuring $\mathrm{CH}_{5(1)}, \mathrm{C} 3$, and $\mathrm{C} 4$.

\section{ISOLATION OF PMNS}

The method was a modification of that of Dioguardi et al. ${ }^{4}$ Fifty millilitres of heparinised blood $(10 \mathrm{U} / \mathrm{ml})$ were diluted with $350 \mathrm{ml}$ of $0.83 \%$ ammonium chloride and allowed to stand for $10 \mathrm{~min}$ at room temperature. After centrifuging at $450 \mathrm{~g}$ for $10 \mathrm{~min}$ the supernatant was discarded and the $\mathrm{NH}_{4} \mathrm{Cl}$ lysis stage repeated. The PMN pellet from the second lysis was washed three times by slow centrifugation (55 $\mathrm{g}$ for $10 \mathrm{~min}$ ) in calcium and magnesium free Hanks's balanced salt solution (CMF-HBSS). This slow centrifugation sediments the large dense PMNs from the smaller less dense lymphocytes which remain in suspension. The absence of divalent cations in the medium prevented any spontaneous aggregation of the PMNs and greatly increased the yield of cells. The final cell pellet was adjusted to $1 \times 10^{6}$ cells $/ \mathrm{ml}$. Cell viability as shown by exclusion of the trypan blue was always $>96 \%$, and the purity of PMNs was approximately $90 \%$.

This method was chosen because it was found to be more rigid than the dextran-Lymphoprep isolation technique used in the preceding paper. The adherence of PMNs was not modified by ammonium chloride treatment.

RADIOLABELLING OF PMNS WITH ${ }^{51} \mathrm{Cr}$ At the end of the last study' we showed that indium-111 ( ${ }^{111}$ In) oxine itself augmented PMN adhesion to endothelial cells. ${ }^{5}$ Although this finding did not alter the interpretation of the results in the preceding paper, ' $\mathrm{PMNs}$ in the present investigation were radiolabelled with ${ }^{51} \mathrm{Cr}$. This radiolabel does not enhance the adherence as does ${ }^{111}$ In oxine. Preliminary studies showed radiolabelling to be most efficient when $100 \mu \mathrm{Ci}(3.7 \mathrm{MBq}){ }^{51} \mathrm{Cr}$ were incubated with $1 \times 10^{\circ} \mathrm{PMNs}$ for one hour at $37^{\circ} \mathrm{C}$ with agitation every $15 \mathrm{~min}$. The radiolabelled PMNs were washed on three occasions by suspending in $5 \mathrm{ml}$ CMF-MBSS supplemented with $5 \%$ fetal calf serum and centrifuging at $450 \mathrm{~g}$ for $10 \mathrm{~min}$.

The final cell pellet was resuspended in $5 \mathrm{ml}$ EMEM (Eagle's minimum essential medium) sup- plemented with $1 \mathrm{mM}$ glutamine, $200 \mathrm{U} / \mathrm{ml}$ penicillin, and $100 \mathrm{U} / \mathrm{ml}$ streptomysin, buffered to $\mathrm{pH} \mathrm{7.3}$ with $10 \mathrm{mM}$ HEPES buffer ( $N$-2-hydroxyethylpiperazine- $N^{\prime}$-2-ethanesulphonic acid) and filtered through $4 \mathrm{~mm}$ metal gauze to remove any large clumps. The viability of PMNs as assessed by trypan blue exclusion was $>96 \%$, and the cell concentration was adjusted to $1 \times 10^{6} \mathrm{cells} / \mathrm{ml}$.

PREPARATION OF ENDOTHELIAL

MONOLAYERS

The method was identical to that described in the preceding paper ${ }^{1}$ except that the final seeding of endothelial cells in the multiwell plates was onto the floor of each chamber and not onto glass coverslips.

\section{A DHERENCE ASSAY}

Medium was aspirated from each well and the confluent endothelial monolayers washed twice with phosphate buffered saline (PBS) at $37^{\circ} \mathrm{C}$ to remove any contaminating fetal calf serum. To each well were added $100 \mu \mathrm{l}$ of labelled PMNs $\left(1 \times 10^{6}\right.$ cells $/ \mathrm{ml}$ ) from normal healthy subjects, $200 \mu \mathrm{l}$ of the

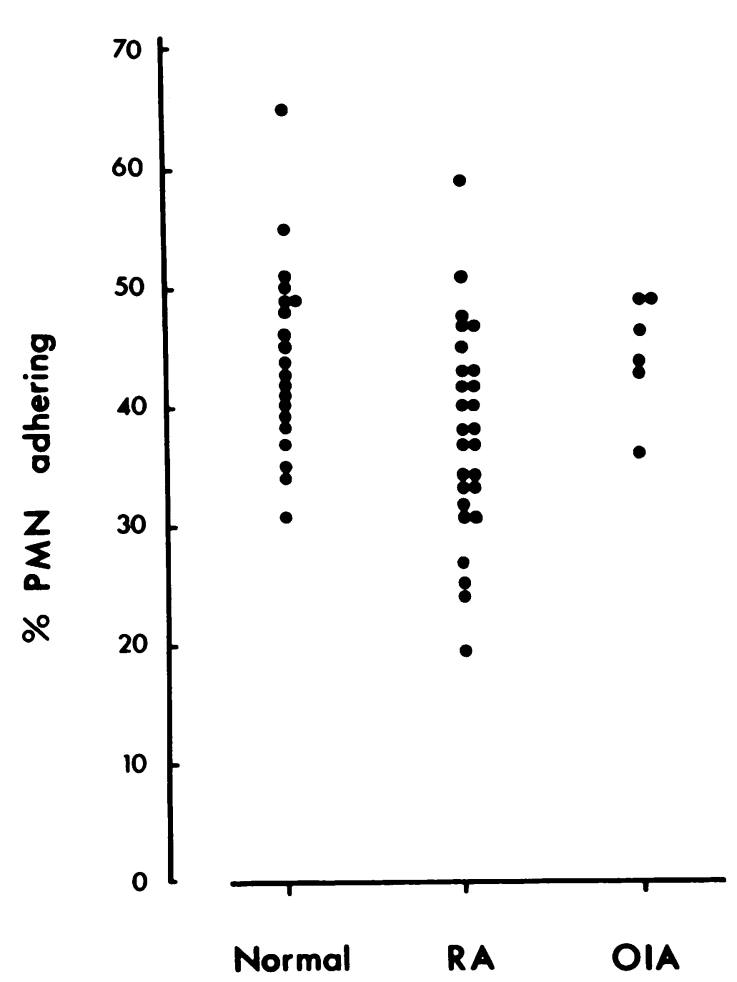

Fig. 1 Comparison of the effect of sera from normal subjects, patients with RA, and patients with other inflammatory arthropathies (OIA) on the adhesion of normal blood PMNs to cultured endothelium. 


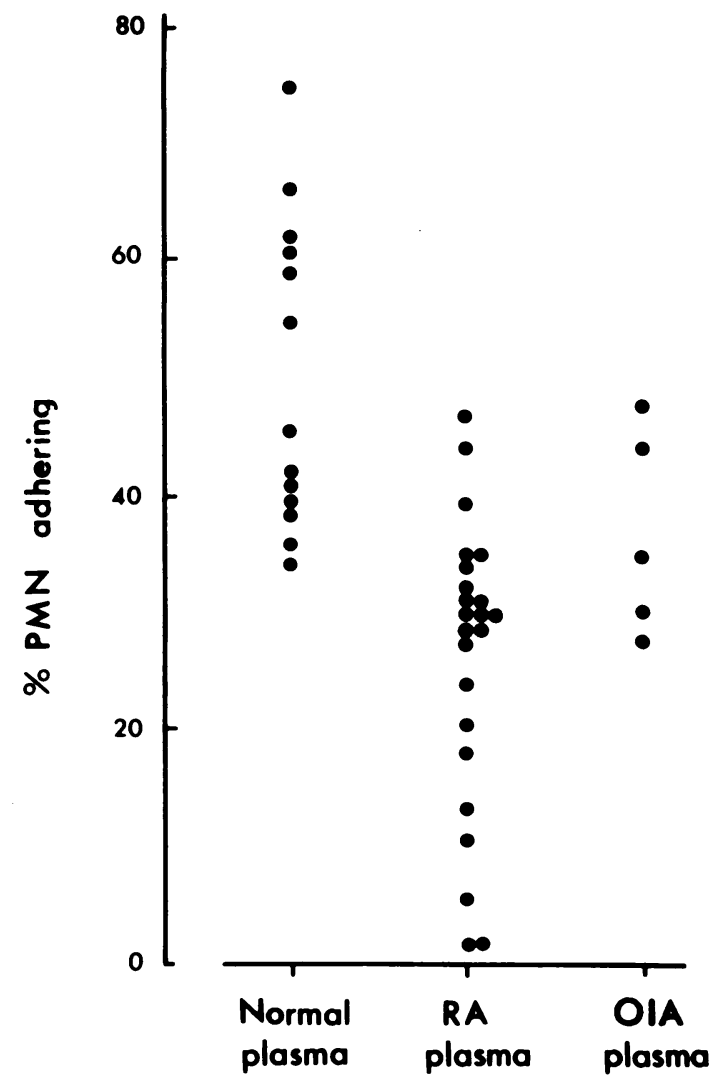

Fig. 2 Comparison of the effect of plasma from normal subjects, patients with $R A$, and patients with other inflammatory arthropathies (OIA) on the adhesion of normal blood PMNs to cultured endothelium.

test serum, and $700 \mu \mathrm{l}$ of EMEM. Each test was performed in triplicate in randomly allotted wells. After incubation at $37^{\circ} \mathrm{C}$ for $60 \mathrm{~min}$ the nonadherent PMNs were aspirated and the endothelial monolayers washed with $\mathrm{PBS}$ at $37^{\circ} \mathrm{C}$ to remove any loosely adherent cells. The endothelium was osmostically disrupted by treatment with $0.5 \mathrm{ml} 0.1 \mathrm{M}$ $\mathrm{NaOH}$ for $15 \mathrm{~min}$. The lysate was aspirated, collected in tubes, and counted in a Packard auto-gamma scintillation counter.

The percentage of PMNs adhering to endothelium was calculated as follows:

$\underset{(\%)}{\text { Adherence }}=\frac{c p m \text { in each well }-\mathrm{cpm} \text { background }}{\mathrm{cpm} \text { of original PMN-cpm background }} \times 100$

PREPARATION OF STABLE HEAT INDUCED AGGREGATED HUMAN IgG (HAGG)

Aggregates of IgG were prepared as described previously. ${ }^{\circ}$ Briefly, human IgG (Sigma) was dissolved in borate buffered saline (BBS) at a concentration of $30 \mathrm{mg} / \mathrm{ml}$ and clarified by centrifugation at $5000 \mathrm{rpm}$ for $10 \mathrm{~min}$. The supernatant was heated at $60^{\circ} \mathrm{C}$ until the absorbance at $40 \mathrm{~nm}$ reached 0.25 units, thereafter it was allowed to stand at $4^{\circ} \mathrm{C}$ for $48 \mathrm{~h}$. The aggregates were selectively concentrated by polyethylene glycol $(7 \%)$ precipitation, washed twice by centrifugation in BBS, and resuspended in $5 \mathrm{ml} \mathrm{BBS}$. The HAGG was concentrated twofold by air drying in dialysis tubing to give a protein concentration of $2 \mathrm{mg} / \mathrm{ml}$ and diluted in EMEM (Gibco) for use as the test media in the adherence assay.

STATISTICAL METHODS

The data were parametric and the Student's $t$ test was used to determine the significance of differences between the means of two groups.

\section{Results}

EFFECT OF RA SERUM AND PLASMA ON PMN ADHERENCE

The results, expressed as the percentage of PMNs adhering to endothelial cells, are shown in Fig. 1.

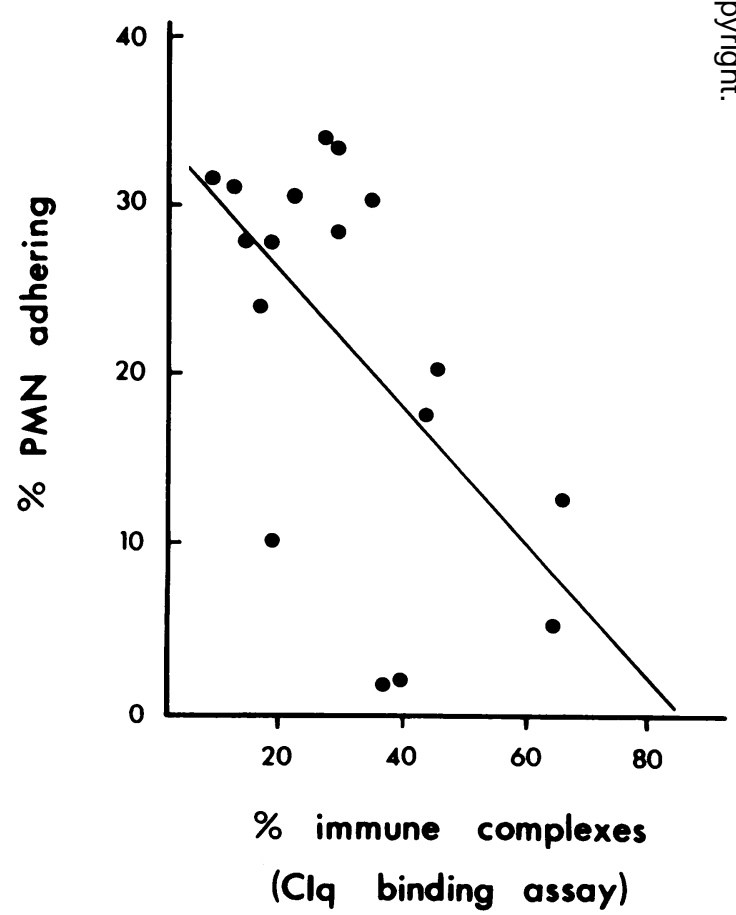

Fig. 3 The relation between the inhibition of $P M N$ adhesion induced by the RA plasma and the level of circulating immune complexes as measured by the Clq binding assay. 
Table 1 Correlation between an inhibition of PMN adherence by RA plasma and various immunological parameters

\begin{tabular}{lll}
\hline Parameter & $r$ Value & Probability \\
\hline Latex titre & -0.353 & $0.5>\mathrm{p}>0 \cdot 1$ \\
IgM RF & -0.333 & $0.5>\mathrm{p}>0 \cdot 1$ \\
IgA RF & -0.500 & $\mathrm{p}<0.05^{*}$ \\
IgG RF & -0.376 & $0.5>\mathrm{p}>0 \cdot 1$ \\
Total immune complexes & & \\
$\quad$ by C1q binding assay & -0.597 & $\mathrm{p}<0.01^{*}$ \\
IgM Clq solid phase assay & -0.001 & $\mathrm{p}>0 \cdot 5$ \\
IgA C1q solid phase assay & -0.351 & $0.5>\mathrm{p}>0.1$ \\
IgG Clq solid phase assay & -0.494 & $\mathrm{p}<0.05^{*}$ \\
\hline
\end{tabular}

*Significant negative correlations.

The mean (SD) percentage adherence for normal PMNs cocultured with $20 \%$ RA serum was 37 $(10) \%$, which was lower $(\mathrm{p}<0 \cdot 01)$ than the mean $(45$ (7)\%) for PMNs cultured with serum from either normal subjects or patients with other inflammatory arthropathies (OIA).

When $20 \%$ plasma was used in place of serum this inhibition was more marked (Fig. 2). With RA plasma there was a mean $22(11) \%$ PMN adhesion in contrast with means of $38(7) \%$ and $48(13) \%$ PMN adhesion induced by plasma from subjects with OIA and normal subjects respectively. There was no significant difference between the effects of OIA and normal plasma on PMN adherence.

Linear regression analysis was used to determine if there was any relation between the extent of adherence inhibition induced by the RA plasma and the patients' clinical and immunological status. There were significant negative correlations between the inhibition of adherence and the level of immune complexes $(p<0.01)$, as measured by the Clq binding assay (Fig. 3), and the level of $\operatorname{IgA}$ rheumatoid factor and immune complexes bearing IgG when measured by the $\mathrm{Clq}$ solid phase assay (Table 1). There was no correlation between the

Table 2 A comparison of the action of RA, OAI, and normal plasma on the adhesion of normal PMNs to monolayers of endothelial cells and serum coated p. Asic

\begin{tabular}{llr}
\hline $\begin{array}{l}\text { Plasma } \\
(n)\end{array}$ & \multicolumn{2}{l}{ Percentage PMN adherence } \\
\cline { 2 - 3 } & Endothelium & Serum coated plastic \\
\hline Normal (3) & $46(8)^{*}$ & $21(9)$ \\
OIA (3) & $43(4)$ & $14(4)$ \\
RA (6) & $30(3)$ & $8(2)$ \\
\hline
\end{tabular}

*Values are mean (SD) percentage PMN adherence. extent of inhibition adherence and any of the other immunological measurements, patients' clinical features, or the type of anti-inflammatory therapy.

INFLUENCE OF SECRETORY PRODUCTS OF ENDOTHELIAL CELLS ON ADHERENCE

The secretion of cyclo-oxygenase derived metabolites of arachidonic acid, particularly prostacyclin, by endothelial cells is reported to inhibit the adherence of PMNs to endothelium. ${ }^{7}$ To investigate if the abrogation of adherence in the present study was owing to the RA plasma inducing the release of such metabolites from endothelium, monolayers of endothelial cells were pretreated with indomethacin (a standard cyclo-oxygenase antagonist) and the effect of the rheumatoid plasma on PMN adherence monitored. Plasma from three patients with RA induced a mean $33 \%$ inhibition of PMN adhesion to untreated endothelial cells, and $37 \%$ inhibition using endothelium that had been pretreated with 10 $\mu \mathrm{g} / \mathrm{ml}$ indomethacin for 24 hours. Thus the inhibi-

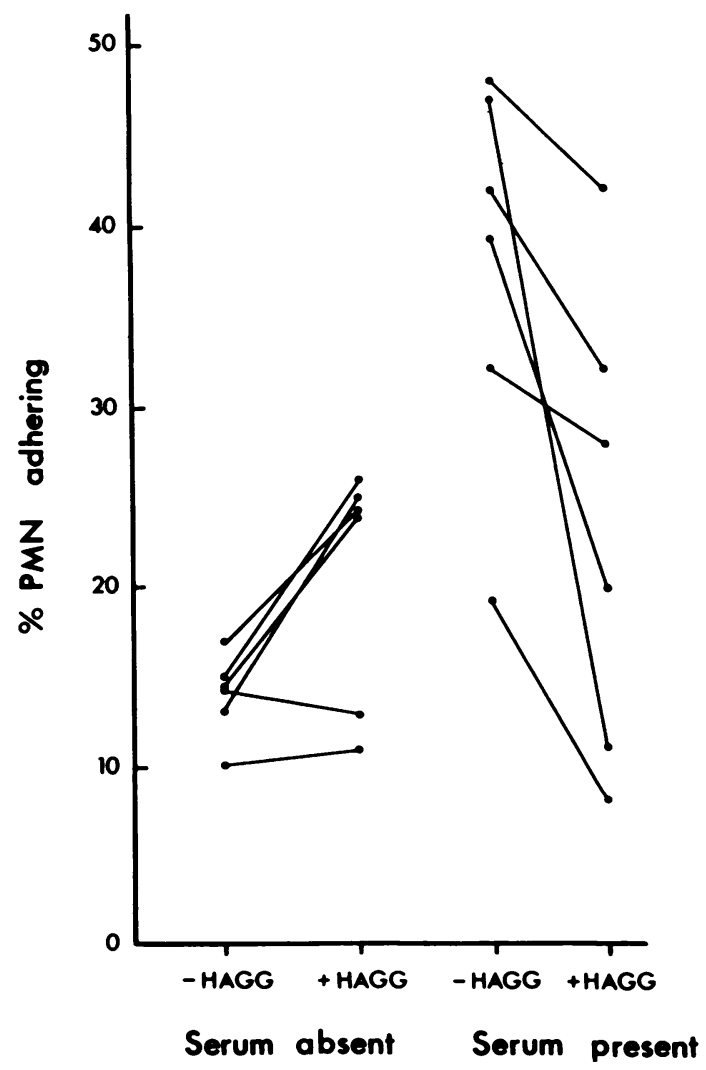

Fig. 4 Heat aggregated $\lg G(H A G G)$ modulation of PMN adherence in the absence and presence of autologous serum. 
tory action of the RA plasma does not appear to be mediated via the release of cyclo-oxygenase products from endothelial cells.

To determine if RA plasma was inducing the release of other products of endothelial cells that might have been modifying the PMN attachment the action of plasma samples from six patients with RA, three patients with OIA, and three normal subjects on PMN adhesion was compared using endothelium and wells of plastic plates (Limbro) incubated with $20 \%$ heat inactivated fetal calf serum for one hour at $37^{\circ} \mathrm{C}$ and rinsed twice with PBS. The RA plasma induced a mean $35 \%(\mathrm{p}<0.05)$ and $62 \%(\mathrm{p}<0.01)$ inhibition of adhesion in the endothelium and serum coated plastic assay respectively when compared with the effect of plasma obtained from normal subjects and patients with OIA (Table 2). This experiment suggests that the inhibition of adhesion induced by the RA plasma was not mediated through the release of endothelial cell secretory products.

EFFECT OF IgG AGGREGATES ON PMN A D H EREN C E

Since stable, heat induced aggregates of IgG (HAGG) are believed to share similar biological properties with immune complexes ${ }^{6}$ we investigated the action of such aggregates on PMN-endothelial cell adherence. In each of six experiments $100 \mu \mathrm{g}$ of HAGG was preincubated with $1 \times 10^{6}$ labelled PMNs for $30 \mathrm{~min}$ at $37^{\circ} \mathrm{C}$. Thereafter, aliquots of the PMN suspension were added to the endothelial cell monolayers. When serum was absent from the culture medium the HAGG induced a mean $33 \%$ increase in adhesion (Fig. 4). In contrast, when $20 \%$ autologous sera were added to the assay the HAGG induced a mean $28 \%$ inhibition of adhesion.

\section{Discussion}

The demonstration that serum and particularly plasma from patients with RA inhibited the adhesion of normal blood PMNs to cultured endothelium repeats the findings of the preceding paper. This inhibition, which was not related to duration of disease, disease activity, or extravascular manifestations, was directly correlated with the level of circulating immune complexes as measured by the Clq binding assay.

An inhibitor of PMN adherence to nylon fibres has been described in the plasma (but not the serum) of patients receiving non-steroidal antiinflammatory drugs. ${ }^{3}$ Such a drug related factor seems unlikely to be responsible for the inhibition noted in the present study since plasma from the patients with OIA, who were also receiving NSAIDs, did not modify PMN adhesion. Moreover, there was no correlation between the type of anti- $\frac{\sigma}{\infty}$

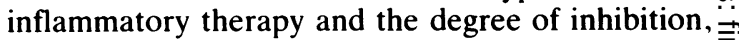
and recent studies in our laboratory show that the incubation of PMNs with NSAIDs in vitro does not? modify their adherence to cultured endothelium (manuscript in preparation).

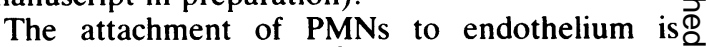
enhanced by complement. ${ }^{8}$ All RA samples tested, however, possessed complement activities that were $\vec{O}$ within the normal range.

A major secretory product of endothelial cells is $\vec{\omega}$ prostacyclin, ${ }^{9}$ which decreases PMN adherence to $\stackrel{\circ}{\circ}$ cultured endothelium ${ }^{7}$ and nylon. ${ }^{10}$ Its synthesis and $\frac{0}{2}$ release by endothelial cells is enhanced by serum, ${ }^{11}$ ? hydrogen peroxide. ${ }^{12} 13$ and leucotrienes. ${ }^{14}$ Because $\stackrel{\circ}{\circ}$ the inhibitory activity of the RA plasma was not 0 modified when the endothelial cell monolayers were ${ }_{\infty}^{\infty}$ pretreated with indomethacin we infer that the secretion of cyclo-oxygenase products, either $\vec{T}$ directly or indirectly, by the release of degranulation $\mathbb{D}$ products from activated PMNs is not involved.

The abrogatory activity induced by the RA serum/plasma appears to be due in part to the level $\vec{D}$ of immune complexes containing IgG, a conclusion that is supported by the demonstration that Is. aggregates also impeded PMN adhesion. Hashimoff응 and Hurd reported that high concentrations of Ig aggregates and immune complexes increased the attachment of PMNs to endothelium when serum was absent from the coculture ${ }^{15}$; a finding that we $\stackrel{\mathbb{Q}}{\mathbb{2}}$ support. As shown in the present report, however, $\overrightarrow{\vec{B}}$ when serum is included in the assay the $\operatorname{IgG}_{3}$ aggregates induced a decrease in PMN adhesion. We therefore propose that in vivo certain circulatingo immune complexes restrict PMN attachment to vascular endothelium. Our preliminary data suggest that this inhibition is mediated via complement. Immune complexes may bind to the $\mathrm{Fc}$ and $\mathrm{C} 3 \mathrm{~b}$ receptors of the PMNs and mask surface ionogenico groups, whose expression is necessary for the cell's interaction with endothelial cells. Experiments are음 in progress to determine if the membranes of PMNs $>$ treated with immune complexes are still accessible to the binding of antibodies directed against such determinants.

At first, an abrogation of PMN interaction with endothelial cells by immune complexes appears tow contravene the clinical observations of a large persistent infiltration of RA blood PMNs into the joint synovial fluid. We speculate, however, tha厉 immune complexes, by restricting the number of? PMNs adhering to endothelium of the generato vasculature, increase the number of cells available to synovial endothelial cells, whose distinct mems brane phenotypes facilitate the margination o $\overrightarrow{\mathbb{Q}}$ 
PMNs bearing immune complexes. Such a mechanism may be implicated in the increased susceptibility of patients with RA to infection, and be relevant to the inflammatory recruitment of other leucocytes. We are currently investigating this possibility.

This work was supported in part by a cooperative award from the Science and Engineering Research Council. NJS was in receipt of a St Thomas's Hospital Trustee Fellowship.

\section{References}

1 Sheehan N J, Brown K A, Perry J D, Chasty R C, Yates D A H, Dumonde D C. Adherence of rheumatoid polymorphonuclear cells (PMNs) to cultured endothelial cell monolayers. Ann Rheum Dis 1987; 46: 93-7.

2 Lentnek A L, Schreiber A D, MacGregor R R. The induction of augmented granulocyte adherence by inflammation. Mediation by a plasma factor. J Clin Invest 1976; 57: 1098-103.

3 MacGregor R R, Spagnuolo P J, Lentnek A L. Inhibition of granulocyte adherence by ethanol, prednisone and aspirin, measured with a new assay system. N Engl J Med 1974; 291: 642-6.

4 Dioguardi N, Agostini A, Fiorelli G, Lomanto B. Characterisation of lactic dehydrogenase of normal human granulocytes. $J$ Lab Clin Med 1963; 61: 713-23.

5 Sheehan N J, Brown K A, Camacho A, Dumonde D C. ( ${ }^{111}$ In), Indium oxine labelling of polymorphonuclear leucocytes: doubts concerning elution and effects on cell behaviour. Int J Nucl Med Biol 1985; 12: 243-7.
6 McCarthy D, Goddard D H, Pell B K, Holborow E J. Intrinsically stable IgG aggregates. J Immunol Methods 1981; 41: 63-74.

7 Boxer L A, Allen J M, Schmidt M, Yoder M, Baehner R L. Inhibition of polymorphonuclear leukocyte adherence by prostacyclin. J Lab Clin Med 1980; 95: 672-8.

$8 \mathrm{Fehr} \mathrm{J}$, Jacob H S. In vitro granulocyte adherence and in vivo margination: two associated complement-dependent functions. Studies based on the acute neutropenia of filtration leukophoresis. J Exp Med 1977; 146: 641-52.

9 Macintyre D E. Pearson J D, Gordon J L. Localisation and stimulation of prostacyclin production in vascular cells. Nature 1978; 271: 549-51.

10 McGillen J, Patterson R, Phair J P. Adherence of polymorphonuclear leukocytes to nylon: modulation by prostacyclin (PGI), corticosteroids and complement activation. J Infect Dis 1980; 141: 382-91.

11 Seid J M, Jones P B B, Russell R G G. The presence in normal plasma, serum and platelets of factors that stimulate the production of prostacyclin (PGI2) by cultured endothelial cells. Clin Sci 1983; 64: 387-94.

12 Agar A, Gordon J. Differential effects of hydrogen peroxide on indices of endothelial cell function. $J$ Exp Med 1984; 159: 592-603.

13 Harlan J, Callahan K S. Role of hydrogen peroxide in the neutrophil-mediated release of prostacyclin from cultured endothelial cells. J Clin Invest 1984; 74: 442-8.

14 Pologe L G. Cramer E B, Pawlosvski N A, Abraham E, Cohn Z A. Scott W A. Stimulation of human endothelial cell prostacyclin synthesis by select leukotrienes. J Exp Med 1984; 160: 1043-53.

15 Hashimoto Y, Hurd E R. Human neutrophil aggregation and increased adherence to human endothelial cells induced by heat-aggregated IgG and immune complexes. Clin Exp Immunol 1981; 44: 538-47. 